\title{
Effects of Chemical Structure Changes on Curing Reactions and Thermal Properties of Cyanate Ester-Cured Rigid-Rod Epoxy Resins
}

\author{
W-F. A. SU, CHIH-MIN CHUANG \\ Department of Materials Science and Engineering, National Taiwan University, Taipei, Taiwan, Republic of China
}

Received 30 May 2001; accepted 28 August 2001

\begin{abstract}
How chemical structure changes affect the curing reactions and thermal properties of 2,2'-bis(4-cyanatophenyl) propane (cyanate ester) cured rigid-rod epoxy resins has been studied for biphenol and tetramethyl biphenol epoxies. The formation of an oxazolidinone ring is the dominant curing reaction for biphenol epoxy, whereas the formation of a cyanurate ring is the dominant curing reaction for tetramethyl biphenol epoxy, due to the bulky methyl substitutions on the biphenol chain. The crosslinkable cyanurate structure has a higher thermal stability than that of the linear oxazolidinone structure, giving the cyanate ester cured tetramethyl biphenol epoxy resin (molar equivalent) a higher glass transition temperature $\left(260 \mathrm{vs} .218^{\circ} \mathrm{C}\right)$ and thermal decomposition temperature $\left(366 \mathrm{vs} .312^{\circ} \mathrm{C}\right)$ than that of cyanate ester cured biphenol epoxy resin. () 2002 Wiley Periodicals, Inc. J Appl Polym Sci 85: 2419-2422, 2002
\end{abstract}

Key words: cyanate ester; epoxy; rigid rod; biphenol; liquid crystalline

\section{INTRODUCTION}

Recently, rigid-rod epoxy resins have been synthesized as a new class of high-performance polymers for electronic and aerospace applications.

The amine, anhydride, or phenolic cured rigidrod epoxies show improved thermal, mechanical, and electrical properties compared to those of flexible bisphenol A epoxies cured by the same type of curing agents. For instance, Ochi et al. ${ }^{1}$ showed that biphenol epoxy cured with phenol novolak and aromatic diamine exhibit increased lap shear strength, adhesive strength, tensile strength, and fracture toughness. $\mathrm{We}^{2}$ cured biphenol epoxies with trimellitic anhydride and diamino diphenylsulfone, respectively. The cured resins exhibited improved thermal and electrical

Correspondence to: W.-F. A. Su (suwf@coms.ntu.edu.tw).

Contract grant sponsor: Chinese Petroleum Corporation; contract grant number: NSC89-CPC7-002-009.

Journal of Applied Polymer Science, Vol. 85, 2419-2422 (2002)

() 2002 Wiley Periodicals, Inc. properties. Sue et al. ${ }^{3}$ obtained high fracture toughness $\left(\mathrm{G}_{\mathrm{IC}}=580 \mathrm{JM}^{-2}\right.$ compared with $\mathrm{G}_{\mathrm{IC}}$ $=180 \mathrm{JM}^{-2}$ for bisphenol A system ) and high tensile modulus when $\alpha$-methyl stilbene epoxy was cured with sulfanilamide. Muller et al. ${ }^{4}$ reported an increased tensile modulus (3070 MPa vs. $2346 \mathrm{MPa}$ for bisphenol A epoxy) when dihydroxy phenyl benzoate epoxy was cured with a hexahydrophthalic anhydride. $\mathrm{We}^{5}$ have found that sulfanilamide cured biphenol epoxies exhibited a liquid crystalline network with a low coefficient of thermal expansion (CTE) of $20.8 \mu \mathrm{m} /$ $\mathrm{m}^{\circ} \mathrm{C}$ and a high glass transition temperature $\left(T_{g}\right)$ of $219^{\circ} \mathrm{C}$; sulfanilamide-cured azomethine epoxy has a low weight loss (39\%) at high temperature $\left(450^{\circ} \mathrm{C}\right)$. Their outstanding thermal properties are suitable for flame-resistant high-performance composites.

Cyanate resins have many excellent properties, such as good thermal stability, high glass transition temperature, and low dielectric constant, but they are very expensive, and have to be 

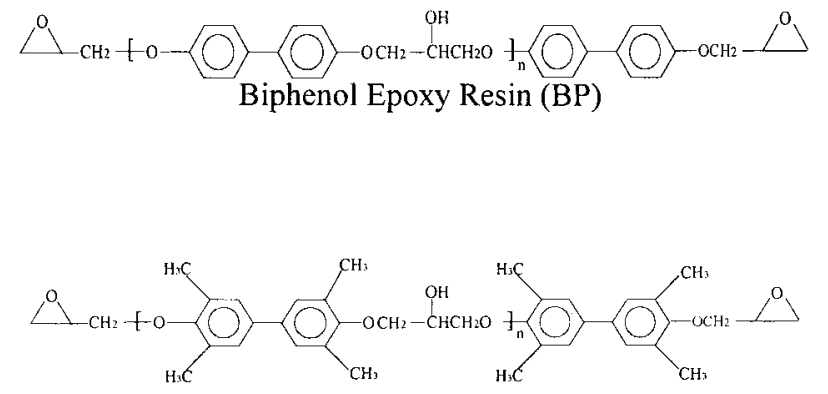

Tetramethyl Biphenyl Epoxy Resin (TMBP)

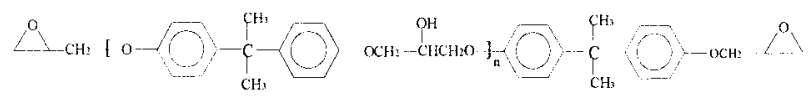

Diglycidyl Ether of Bisphenol A (DGEBA)

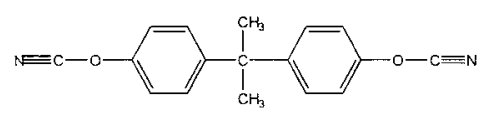

2,2'-bis(4-cyanatophenyl)propane (B10)

Figure 1 Chemical structures of epoxy resins and cyanate ester.

processed at high temperature. ${ }^{6}$ Thus, we have cured rigid-rod epoxies by cyanate ester to minimize costs of an easily processed high-performance resin. Figure 1 shows the chemical structures of the investigated epoxy resins and cyanate ester. Effects of chemical structure changes on the curing reactions and thermal properties of cyanate ester cured rigid-rod epoxy resins have been investigated in detail, and are reported in the following sections.

\section{EXPERIMENTAL}

Biphenol epoxy [4,4'-bis(2,3-epoxypropoxy) biphenyl] (BP) was synthesized according to our previously reported procedure. ${ }^{7}$ Tetramethyl biphenol epoxy (trade name RSS1407), with an epoxy equivalent of 185, was supplied by Shell Chemical. Bisphenol A epoxy (trade name DER 331), with an equivalent epoxy weight of 186 , was supplied by Dow Chemical Company. Cyanate ester (AroCy B-10), with cyanate equivalent weight 139, was supplied by Ciba-Geigy Company. Cop- per acetoacetate was purchased from the Aldrich Chemical Company.

The epoxy resins were melt mixed with the appropriate amounts of cyanate ester. Copper acetoacetate catalyst $(0.1 \%$ of total weight of epoxy resin and cyanate ester) was used in preparing all the samples. The curing schedule and the degree of curing of each sample were determined by DSC and DMA. Table I lists the curing schedule of each sample.

DuPont 9900 Series, Model 954 TGA (at $10^{\circ} \mathrm{C} /$ min in $\mathrm{N}_{2}$ ), Model $910 \mathrm{DSC}$ (in $\mathrm{N}_{2}$ at $10^{\circ} \mathrm{C} / \mathrm{min}$ ), Model 983 DMA (in $\mathrm{N}_{2}$ at $2^{\circ} \mathrm{C} / \mathrm{min}$, at $1 \mathrm{~Hz}$ frequency and $0.2 \mathrm{~mm}$ magnitude of vibration), and Model 943 TMA were used to evaluate the thermal properties of the epoxy resins. TMA $T_{g}$ of the samples was determined using the tangent of the slope change (plot of dimension vs. temperature) upon heating. DMA $T_{g}$ of the samples was determined by the $\tan \delta$ max (ratio of loss modulus over storage modulus) of DMA thermograms.

MAGNA-IR 550 Fourier Transform Infrared Spectrometer was used to determine the amount of cyanurate and oxazolidinone structures in the cured samples.

\section{RESULTS AND DISCUSSION}

The curing reactions between cyanate esters and epoxy resin have been proposed by Bauer pathways $^{7,8}$ that involve: (1) cyanurate formation through trimerization of cyanate ester, (2) insertion of glycidyl ether epoxide into aryl cyanurate, (3) rearrangement of aryl cyanurate into alkyl isocyanurate, (4) oxazolidinone formation through the reaction of epoxy and cyanate ester. To determine which is the dominant reaction-cyanurate formation or oxazolidinone formation during the curing of rigid epoxy resin with cyanate ester-we have prepared samples using three molar ratios of epoxy to cyanate ester. The cured samples were monitored using FTIR. The structures of cyanu-

Table I Curing Conditions of Different Epoxy Resins

\begin{tabular}{ll}
\hline $\begin{array}{l}\text { Epoxy } \\
\text { Resin }\end{array}$ & Curing temperature and curing time \\
\hline DGEBA & $130^{\circ} \mathrm{C} / 6 \mathrm{~h}+175^{\circ} \mathrm{C} / 6 \mathrm{~h}+200^{\circ} \mathrm{C} / 6 \mathrm{~h}$ \\
TMBP & $130^{\circ} \mathrm{C} / 6 \mathrm{~h}+200^{\circ} \mathrm{C} / 6 \mathrm{~h}+230^{\circ} \mathrm{C} / 6 \mathrm{~h}$ \\
BP & $130^{\circ} \mathrm{C} / 6 \mathrm{~h}+150^{\circ} \mathrm{C} / 6 \mathrm{~h}+175^{\circ} \mathrm{C} / 6 \mathrm{~h}$ \\
& $+200^{\circ} \mathrm{C} / 6 \mathrm{~h}$ \\
\hline
\end{tabular}


Table II IR Transmittance Peak Area and Ratio of Cyanurate to Oxazolidinone of Epoxy Resins Cured by Cyanate Ratio in Three Molar Ratios

\begin{tabular}{|c|c|c|c|c|}
\hline Epoxy : Cyanate ester & Epoxy Resin & $\begin{array}{c}\text { Cyanurate at } \\
1564 \mathrm{~cm}^{-1}\end{array}$ & $\begin{array}{l}\text { Oxazolidinone } \\
\text { at } 1750 \mathrm{~cm}^{-1}\end{array}$ & $\begin{array}{c}\text { Ratio of } \\
\text { Cyanurate to } \\
\text { Oxazolidinone }\end{array}$ \\
\hline \multirow[t]{3}{*}{$1: 0.5$} & DGEBA & 74.98 & 828.38 & 0.090 \\
\hline & TMBP & 27.31 & 410.80 & 0.066 \\
\hline & $\mathrm{BP}$ & 5.24 & 380.94 & 0.013 \\
\hline \multirow[t]{3}{*}{$1: 1$} & DGEBA & 114.29 & 307.55 & 0.371 \\
\hline & TMBP & 247.01 & 214.44 & 1.151 \\
\hline & $\mathrm{BP}$ & 113.40 & 318.26 & 0.356 \\
\hline \multirow[t]{3}{*}{$1: 2$} & DGEBA & 450.63 & 329.71 & 1.366 \\
\hline & TMBP & 409.64 & 114.42 & 3.580 \\
\hline & $\mathrm{BP}$ & 411.52 & 416.67 & 0.987 \\
\hline
\end{tabular}

rate and oxazolidinone have IR absorption peaks at $1564 \mathrm{~cm}^{-1}$ and $1750 \mathrm{~cm}^{-1}$, respectively. The flexible bisphenol A epoxy was included in the study for the purpose of comparison. The results are summarized in Table II.

When the sample contains excess epoxy resin (molar ratio of epoxy to cyanate ester $=1: 0.5$ ), the peak ratio of cyanurate to oxazolidinone is less than 0.10. Therefore, the oxazolidinone formation is the dominant curing reaction for samples containing excess epoxy resin. On the other hand, when the samples contain excess cyanate ester (molar ratio of epoxy to cyanate ester $=1$ : 2 ), the peak ratio of cyanurate to oxazolidinone is greater than 0.99 . The formation of cyanurate is clearly the dominant curing reaction in this case. However, chemical structure changes in the epoxy resin have the largest effect on the curing reactions. Regardless of the molar ratio of epoxy to cyanate ester, tetramethyl biphenol epoxy has the highest rate of cyanurate formation among all

Table III Glass Transition Temperatures of Cyanate Ester Cured Epoxy Resins in Three Molar Ratios

\begin{tabular}{clcc}
\hline $\begin{array}{c}\text { Epoxy : Cyanate } \\
\text { Ester }\end{array}$ & $\begin{array}{c}\text { Epoxy } \\
\text { Resin }\end{array}$ & $\begin{array}{c}\text { DMA } T_{g} \\
\left({ }^{\circ} \mathrm{C}\right)\end{array}$ & $\begin{array}{c}\text { TMA } T_{g} \\
\left({ }^{\circ} \mathrm{C}\right)\end{array}$ \\
\hline \multirow{2}{*}{$1: 0.5$} & DGEBA & 187 & 100 \\
& TMBP & 234 & 168 \\
$1: 1$ & BP & 184 & 164 \\
& DGEBA & 237 & 200 \\
& TMBP & 260 & 219 \\
$1: 2$ & BP & 218 & 199 \\
& DGEBA & 257 & 205 \\
& TMBP & 270 & 235 \\
& BP & 240 & 207 \\
\hline
\end{tabular}

three epoxies. The bulky tetramethyl group retarded the reaction rate greatly between the epoxy and cyanate ester, as shown in the samples with an equivalent ratio and excess ratio of cyanate ester to epoxy. When we compared the same molar ratio samples with different type of epoxies, biphenol epoxy had the lowest cyanurateto-oxazolidinone peak ratio. The flexible bisphenol A epoxy has its peak ratio in the middle range, and tetramethyl biphenol epoxy has the highest ratio. Therefore, comparing the reaction rate between epoxy and cyanate ester, biphenyl epoxy is the highest, bisphenol A epoxy next, and tetramethyl biphenol epoxy is the lowest. The biphenol epoxy has a higher reaction rate than that of bisphenol A epoxy, which may be due to the ordered structure of rigid rod biphenol epoxy with a high kinetic reaction rate.

The cyanurate structure has a crosslinking capability to form three-dimensional networks,

Table IV Coefficients of Thermal Expansion (CTE) of Cyanate Ester-Cured Epoxy Resins in Three Molar Ratios

\begin{tabular}{llcc}
\hline \multirow{2}{*}{$\begin{array}{c}\text { Epoxy : } \\
\text { Cyanate }\end{array}$} & Epoxy & \multicolumn{2}{c}{$\operatorname{CTE}\left(\mu \mathrm{m} / \mathrm{m}^{\circ} \mathrm{C}\right)$} \\
\cline { 3 - 4 } Ester & Resin & $\alpha_{1}$, Below $T_{g}$ & $\alpha$, Above $T_{g}$ \\
\hline \multirow{2}{*}{$1: 0.5$} & DGEBA & 97.4 & 1350 \\
& TMBP & 67.1 & 128 \\
& BP & 63.3 & 264 \\
$1: 1$ & DGEBA & 71.6 & 297 \\
& TMBP & 64.9 & 141 \\
& BP & 63.1 & 194 \\
$1: 2$ & DGEBA & 68.0 & 262 \\
& TMBP & 64.4 & 198 \\
& BP & 63.7 & 213 \\
\hline
\end{tabular}


Table V 5\% Weight Loss Temperatures and Residual Weights of Cyanate Ester-Cured Epoxy Resins in Three Molar Ratios

\begin{tabular}{llcc}
\hline Epoxy : & \multicolumn{3}{c}{$5 \%$} \\
$\begin{array}{c}\text { Weight } \\
\text { Cyanate } \\
\text { Ester }\end{array}$ & $\begin{array}{c}\text { Epoxy } \\
\text { Resin }\end{array}$ & $\begin{array}{c}\text { Loss at } \\
T\left({ }^{\circ} \mathrm{C}\right)\end{array}$ & $\begin{array}{c}\text { Residual Weight } \\
\text { at } 450^{\circ} \mathrm{C}(\%)\end{array}$ \\
\hline \multirow{2}{*}{$1: 0.5$} & DGEBA & 344.3 & 16.80 \\
& TMBP & 361.4 & 19.39 \\
& BP & 309.9 & 27.00 \\
$1: 1$ & DGEBA & 344.7 & 23.80 \\
& TMBP & 366.2 & 26.26 \\
& BP & 312.4 & 28.81 \\
& DGEBA & 345.4 & 35.40 \\
& TMBP & 366.3 & 37.57 \\
& BP & 320.5 & 34.95 \\
\hline
\end{tabular}

whereas the oxazolidinone structure forms polymer chains in a linear fashion; samples with a high concentration of cyanurate structure are expected to have a better thermal stability than those samples with high concentration of oxazolidinone structure. In Tables III, IV, and V, it is shown that, for the same type epoxy, the thermal stability of cured samples increases with increasing cyanate ester concentration (i.e., increasing cyanurate concentration). For different epoxies with the same cyanate ester concentration, tetramethyl biphenol epoxy has the highest concentration of cyanurate concentration and exhibited the highest $T_{g}\left(260^{\circ} \mathrm{C}\right)$ and thermal decomposition temperature $\left(366^{\circ} \mathrm{C}\right)$.

The TMA $T_{g}$ of rigid-rod biphenol epoxy is higher than that of flexible bisphenol A epoxy (Table III). The coefficient of thermal expansion of rigid rod biphenol epoxy is the lowest $(63 \mu \mathrm{m} /$ $\mathrm{m}^{\circ} \mathrm{C}$ ) among the test samples before $T_{g}$, and is also lower than that of the flexible bisphenol $\mathrm{A}$ epoxy after $T_{g}$ (Table IV). When the molar ratio of epoxy to cyanate ester is less than or equal to 1 : 1 , the rigid-rod biphenol epoxy has the highest residual weight $(29 \%)$ at $450^{\circ} \mathrm{C}$ (Table V). Unusual thermal properties of rigid-rod biphenol epoxy may be explained by its highly ordered liquid crystalline structure. The cured biphenol epoxy has a more densely packed structure and less free volume than other epoxies that results in less intermolecular motions. The balance of intramolecular and intermolecular motions determines thermal properties of polymers. The cyanurate structure restricts the intramolecular motions, and the rigid-rod biphenol structure restricts the intermolecular motions. Therefore, the overall thermal properties of cyanate ester-cured epoxies are dependent on the chemical structures of the epoxies. Thermal instability of the oxazolidinone structure in the rigid-rod biphenol epoxy can be compensated by using highly ordered rigid-rod structures that are more thermally stable, especially in samples cured with less than a molar equivalent of cyanate ester.

In summary, the ranking of thermal stability of cyanate ester-cured epoxies in decreasing order is: tetramethyl biphenol epoxy $>$ biphenol epoxy $>$ bisphenol A epoxy.

\section{CONCLUSIONS}

The competition between cyanurate formation and oxazolidinone formation during the curing process of epoxy resin and cyanate ester is dependent on the chemical structure of the epoxy resin. The rate of cyanurate formation is the highest for bulky substituted tetramethyl and is the lowest for biphenol epoxy. The thermal stability of cured samples is dependent on the amount of crosslinkable cyanurate structure in the samples, so tetramethyl biphenol epoxy is the most stable and the biphenol epoxy is the least stable. The highly ordered structure of rigid rod biphenol epoxy has been shown by the properties of low coefficient of thermal expansion and high residual weight.

Financial support from Chinese Petroleum Corporation under the grant of NSC89-CPC7-002-009 is highly appreciated.

\section{REFERENCES}

1. Ochi, M.; Shimizu, Y.; Nakanishi, Y.; Murata, Y. J Polym Sci Part B Polym Phys 1997, 35, 397.

2. Su, W.-F. A. J Polym Sci Part A Polym Chem 1993, $31,3251$.

3. Sue, H. J.; Earls, J. D.; Hefner, R. E., Jr. J Mater Sci 1997, 32, 4031.

4. Muller, H. P.; Gipp, R.; Heine, H. U.S. Pat. 4764581 (1988).

5. Su, W.-F. A.; Chen, K. C.; Tseng, S Y. J Appl Polym Sci 2000, 78, 446.

6. Lin, S.-C.; Pearce, E. M. High Performance Thermosets, Chemistry, Properties, Applications; Hanser: New York, 1994, chapt 3.

7. Bauer, J.; Bauer, M. J Macromol Sci Chem 1990, A27, 97.

8. Lin, R. H. J Polym Sci Part A Polym Chem 2000, $38,2934$. 